\title{
A Rare Case of Tolosa Hunt
}

\author{
Mahendra Tilkar¹, Tapasaya Nanda², Vaibhav Meshram³
}

${ }^{1}$ Associate Professor, Department of General Medicine, Sanjay Gandhi Medical College, Shyam Shah Medical College, Rewa, Madhya Pradesh, India. ${ }^{2} 3^{\text {rd }}$ Year Postgraduate Student, Department of General Medicine, Sanjay Gandhi Medical College, Shyam Shah Medical College, Rewa, Madhya Pradesh, India. ${ }^{3} 3^{\text {rd }}$ Year Postgraduate Student, Department of General Medicine, Sanjay Gandhi Medical College, Shyam Shah Medical College, Rewa, Madhya Pradesh, India.

\section{INTRODUCTION}

Tolosa-Hunt Syndrome is a rare clinical entity, the exact pathology of which is still unknown. THS is caused by a non-specific inflammatory process in the cavernous sinus or superior orbital fissure (SOF). Although painful ophthalmoplegia is not rare, THS as a cause of painful ophthalmoplegia has been considered as a rare clinical entity. The etiopathogenesis of THS largely remains unknown. No exact information is available on what actually triggers the acute inflammatory process within the cavernous sinus/superior oblique fissure. Thus, the syndrome can be taken as a manifestation of idiopathic orbital inflammation (Pseudotumor).[7] The syndrome of painful ophthalmoplegia consists of periorbital or hemicranial pain combined with ipsilateral ocular motor nerve palsies, oculosympathetic paralysis, and sensory loss in the distribution of the ophthalmic and occasionally the maxillary division of the trigeminal nerve. Various combinations of these cranial nerve palsies may occur, localizing the pathological process to the region of the cavernous sinus/superior orbital fissure. We are presenting a case report on THS. The patient presented with complete ptosis, unilateral headache and diminished vision. On examination, there was complete ophthalmoplegia and diminished sensation over the area supplied by $1^{\text {st }}$ and $2^{\text {nd }}$ division of trigeminal nerve. CEMRI brain revealed enhancing soft tissue thickening along right cavernous sinus extending to right orbital apex without any e/o filling defect in cavernous sinus or dilated SOV suggestive of THS. Other differential diagnoses were excluded on the basis of careful history, examination and investigations.

In 1966, Smith and Taxdal applied the eponym "Tolosa-Hunt Syndrome".[1] Tolosa-Hunt Syndrome is a rare clinical entity with annual incidence 1 per million worldwide ${ }^{[2]}$ which is characterized by unilateral headache or retro orbital pain with palsy of multiple cranial nerves mainly 2nd, 3rd, 4th, first division of 5 th and occasionally second division of 5 th cranial nerve with significant improvement with steroids. In most cases, aetiology is unknown. In 1954, Tolosa[3] reported the first patient with this syndrome, who presented with left orbital pain, ipsilateral progressive visual loss, total left ophthalmoplegia, and reduced sensation over the first division of the trigeminal nerve. After 7 years of this, in 1961, Hunt et al.[4] described this clinical entity, on the basis of six patients. It is an idiopathic condition which develops due to non-specific granulomatous inflammatory process in the region of the cavernous sinus/superior orbital fissure.

Tolosa-hunt syndrome is a rare clinical entity with annual incidence 1 per million worldwide 2 which is characterized by unilateral headache or retro orbital pain with palsy of multiple cranial nerves mainly 2nd, 3rd, 4th, first division of 5th and occasionally second division of 5 th cranial nerve with significant improvement with steroid. We are presenting a case report on Tolosa Hunt syndrome, A 60-year-old female presented with right sided headache and complete ptosis on examination Pupil was non reacting to light. In 1988, THS criteria were provided by the International Headache Society (IHS), and further revised in $2004[5,6]$ as follows-

A. One or more episodes of unilateral orbital pain persisting for weeks if untreated.

B. Paresis of one or more of the third, fourth and/or sixth cranial nerves and/or demonstration of granulomas by MRI or biopsy.

C. Paresis coincides with the onset of pain or follows it within 2 weeks.

D. Pain and paresis resolve within 72 hours when treated adequately with corticosteroids.

E. Other causes have been excluded by appropriate.
Corresponding Author:

Dr. Tapasaya Nanda,

PG Girls Hostel,

SSMC, Rewa,

Madhya Pradesh, India.

E-mail: gmcmonu18@gmail.com

DOI: $10.14260 / j e m d s / 2019 / 614$

Financial or Other Competing Interests: None.

How to Cite This Article:

Tilkar M, Nanda T, Meshram V. A rare case of tolosa hunt. J. Evolution Med. Dent. Sci. 2019;8(36):2828-2830,

$10.14260 / \mathrm{jemds} / 2019 / 614$

Submission 11-07-2019,

Peer Review 24-08-2019,

Acceptance 30-08-2019,

Published 09-09-2019. 


\section{PRESENTATION OF CASE}

A 60-years-old woman presented to the medicine OPD with sudden onset of right sided headache since 7 days followed by drooping of the right upper eyelid since 5 days. The headache was sudden in onset, throbbing in nature involving the right half of head and around the right eye, extending to frontal and temporal region and not associated with nausea and vomiting. After 2 days, patient developed ptosis of right eye. Patient was non-diabetic and non-hypertensive. There was no history of head trauma. On examination, the patient was afebrile, with a pulse rate of 82 beats/min and blood pressure of 130/80 mmHg. There were no signs of pallor, icterus, cyanosis, clubbing, raised jugular venous pressure, or pedal oedema. She was conscious and oriented and other higher mental functions were normal. On ocular examination, there was complete ptosis on the right side at the time of presentation. On eye examination visual acuity of both eye is 6/9. Pupil was nonreactive to light. Medial rectus palsy of right eye is present on examination. Patient is unable to lift his right sided eye lid.

Examination of other cranial nerves was normal. Other system examination was essentially normal. Both direct and indirect pupillary reflexes were absent on right side initially but with start of steroid therapy, pupil became mid dilated and started sluggishly reacting to light.
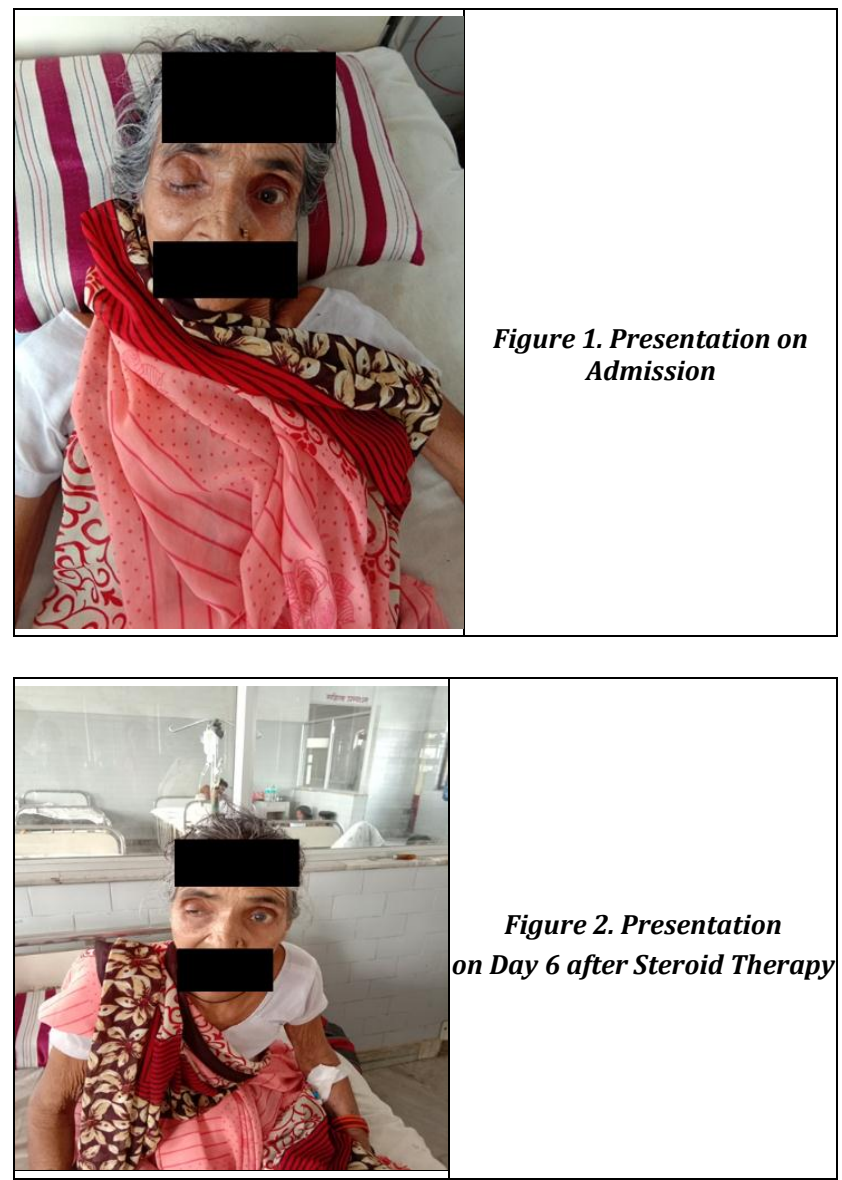

\section{PATHOLOGICAL DISCUSSION}

Her haemoglobin was $11.3 \mathrm{gm} / \mathrm{dL}$, with total leucocyte count of $6800 /$ cumm with differential count $62 / 12 / 2 / 1$, normal platelet count 1.6 lac. Blood sugar was $96 \mathrm{mg} / \mathrm{dL}$ with normal liver and renal function test. Her ESR was $06 \mathrm{~mm}$. Human immunodeficiency virus testing by enzyme-linked immunosorbent assay was negative. ANA testing was found to be negative. Cerebrospinal fluid (CSF) routine and microscopic finding is within normal limit. ECG, X-ray chest, and ultrasound abdomen revealed no abnormal findings.

Moderate enhancing mild soft tissue thickening seen involving anterior part of bilateral cavernous sinuses and bilateral superior orbital fissure right more than left likely acute inflammatory aetiology? Acute stage of Tolosa Hunt syndrome.

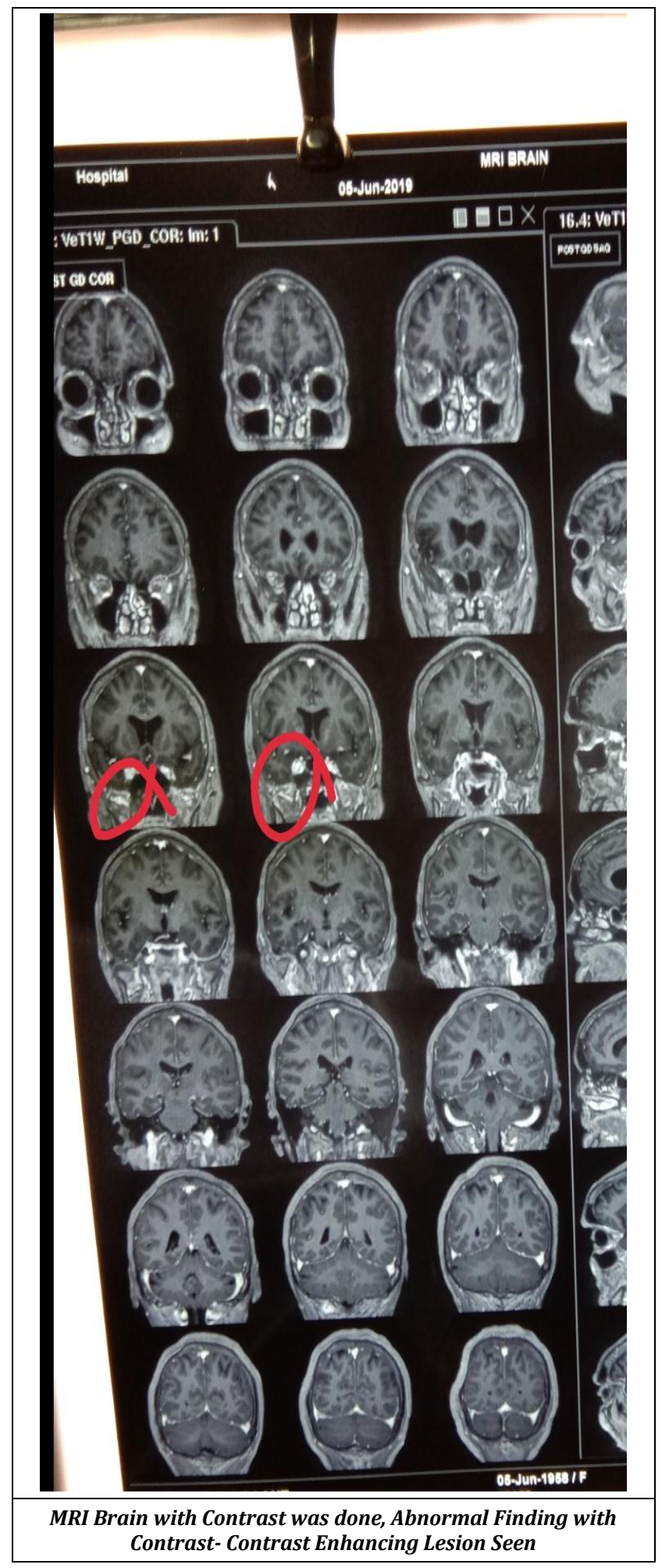




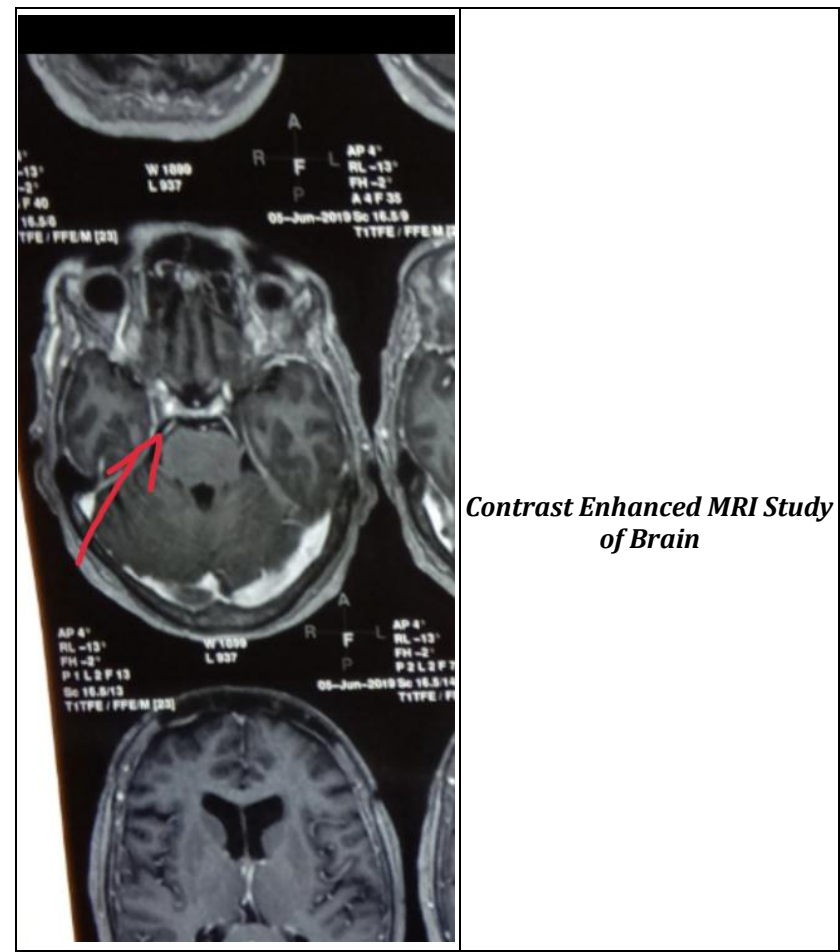

Neuro-imaging - in particular MRI - is an essential part of the workup of any patient presenting with features of THS, as these features are non-specific and have a wide differential diagnosis, including meningioma, sarcoidosis, pituitary tumours, tuberculous meningitis (TBM) and lymphoma. ${ }^{[8]}$

MRI findings classically demonstrate a soft-tissue mass lesion involving the SOF or cavernous sinus. Signal characteristics are typically hypointense to fat and isointense to muscle on short TR/TE sequences and isointense to fat on long TR/TE sequences. ${ }^{[9]}$ Significant enhancement of the mass lesion is demonstrated on CE sequences. Of particular value is the post-contrast fat-saturated thin-slice coronal images through the orbital apex and cavernous sinus.

\section{DISCUSSION OF MANAGEMENT}

We started treatment with steroid. Response was very quick. Within 24 hours there was symptomatic relief in pain and within 6 days there was reverting of ptosis.

\section{CONCLUSIONS}

Tolosa hunt syndrome is a diagnosis of exclusion. Careful history taking, examination, positive neuroimaging finding, and steroid response are considered for diagnosis.

\section{REFERENCES}

[1] Smith JL, Taxdal DS. Painful ophthalmoplegia. The TolosaHunt syndrome. Am J Ophthalmol 1966;61(6):1466-72.

[2] Iaconetta G, Stella L, Esposito $M$, et al. Tolosa-Hunt syndrome extending in the cerebello-pontine angle. Cephalalgia 2005;25(9):746-50.

[3] Tolosa E. Periarteritic lesions of the carotid siphon with the clinical features of a carotid infraclinoid aneurysm. J Neurol Neurosurg Psychiatry 1954;17(4):300-2.

[4] Hunt WE, Meagher JN, Lefever HE, et al. Painful ophthalmoplegia. Its relation to indolent inflammation of the cavernous sinus. Neurology 1961;11:56-62.

[5] Mendez JA, Arias CR, Sanchez D, et al. Painful ophthalomoplegia of the left eye in a 19-year-old female, with an emphasis on Tolosa-Hunt syndrome: a case report. Cases Journal 2009;2:8271.

[6] Mora-de-Onate J, Pascual-Perez-Alfaro R, IzquierdoVazquez C, et al. Painful ophthalmoplegia (pseudotumour of the orbit and Tolosa-Hunt Syndrome). Arch Soc Esp Oftalmol 2007;82(8):509-12.

[7] Levy IS, Wright JE, Lloyd GA. Orbital and retro-orbital pseudo-tumours. Mod Probl Ophthalmol 1975;14:364-7.

[8] Sathyanathan BP, Rajasundaram R, Sankaravadivelu ST, et al. A case of Tolosa-Hunt Syndrome MR imaging appearance. Ind J Radiol Imag 2006;16(1):97-8.

[9] Yousem DM, Atlas SW, Grossman RI, et al. MR imaging of Tolosa-Hunt syndrome. Am J Roentgenol 1990;154(1):167-70. 